\title{
High throughput extraction of plasma using a secondary flow-aided inertial microfluidic device
}

\author{
Jun Zhang, ${ }^{a}$ Sheng Yan, ${ }^{a}$ Weihua Li, ${ }^{a}$ Gursel Alici ${ }^{a}$ and Nam-Trung Nguyen ${ }^{* b}$ \\ Received (in $X X X, X X X)$ Xth $X X X X X X X X X 20 X X$, Accepted Xth $X X X X X X X X X 20 X X$ \\ s DOI: 10.1039/b000000x
}

In this paper, we report the development of a simple inertial microfluidic device with serpentine channel for efficiently separating blood cells from plasma. The working mechanism of this device relies on the two-sided secondary flow aided inertial focusing of particles in a serpentine channel. Specifically, blood cells were focused along two sides of channel, while the blood plasma was collected at the cell-free 10 region within the channel centre. The device was tested with diluted (1/20) whole blood. A relatively high flow rate of $350 \mu \mathrm{l} / \mathrm{min}$ with a purity of $\sim 99.75 \%$ was achieved in a single process. A further improvement to $99.95 \%$ purity was obtained after a second process. Parallelization with eight parallel serpentine channels achieved a high flow rate of $2.8 \mathrm{ml} / \mathrm{min}$ and a massive throughput of $7 \times 10^{8}$ cells $/ \mathrm{min}$. Our device could be easily integrated with other sample preparation processes or detection units to form a 15 sample-to-answer lab-on-a-chip system.

\section{Introduction}

Plasma is a host of various analytes such as proteins, metabolites, circulating nucleic acids (CNAs), pathogens etc. The plasma needs to be cell-free for the effective detection of these analytes.

20 The key process of plasma extraction is to eliminate the contamination from blood cells (erythrocytes, leukocytes and platelets). ${ }^{1}$ In human whole blood, blood plasma is a strawcoloured liquid component, which normally makes up about $55 \%$ of the whole blood volume. Although conventional methods 25 including macroscale centrifugation and membrane filtration can provide efficient removal of blood cells, they are still facing some limitations. For example, centrifugation is generally labourintensive, time consuming and even dangerous to some extent (containing high speed rotating components), and needs to be 30 operated by well-trained staff. Membrane filtration suffers the problem of severe clogging due to the finite filtration capacity, and frequent rinse is lab-intensive and undesirable. ${ }^{2}$

The recently emerged microfluidic technology, which manipulates fluid and particles at microscale and single particle

35 level, provides a better opportunity for this task due to the many advantages over conventional technologies, such as smaller volume of sample, faster sample processing, higher sensitivity, lower cost and improved portability. ${ }^{3,} 4$ More importantly, microfluidics can potentially integrate various functional 40 components (i.e. actuator, ${ }^{5}$ mixer, ${ }^{6}$ sorter $^{7}$ and detector ${ }^{8}$ ) into a single device for automating sample preparation and analysis, eliminating possible human errors. Currently, there are a variety of developed techniques to process biological samples in the microfluidic format. According to the requirement of external 45 force fields, they can be classified as active and passive techniques. Active techniques need external force fields, such as acoustic, ${ }^{9}$ electric ${ }^{10}$ and magnetic force, ${ }^{11}$ to manipulate or separate particles. Although active techniques can provide more flexible and precise manipulation on particles, they are normally 50 limited by the low throughput, complex fabrication and expensive auxiliary equipment. ${ }^{2}$ Whereas passive techniques depend on the channel geometry or intrinsic gravity and hydrodynamic forces. Thus, they are much simpler and cheaper. To date, several passive techniques have been proposed, such as the sedimentation $55,{ }^{12}$ microfiltration, ${ }^{13},{ }^{14}$ deterministic lateral displacement (DLD),${ }^{15,16}$ hydrophoresis ${ }^{17}$ and inertial microfluidics. ${ }^{18}$

Sedimentation is a most simple method, which employs the difference of density between blood cells and plasma. Since the density of blood cells $\left(\rho_{R B C s}=1100\right.$ and $\rho_{W B C s}=1050-1090 \mathrm{~kg} \mathrm{~m}^{-}$ $\left.{ }_{60}{ }^{3}\right)$ is larger than that of plasma $\left(\rho_{\text {plasma }}=1030 \mathrm{~kg} \mathrm{~m}^{-3}\right)$, blood cells can gradually settle down by gravity. However, its throughput is normally very low $\left(0.1 \sim 1 \mu \mathrm{min}^{-1}\right){ }^{12,} 19$ Microfiltration, a transformation of membrane filter in microfluidic format, is working based on its well-defined pore sizes. ${ }^{13}$ Particles larger ${ }_{65}$ than the pore size will be retained, and smaller ones can pass through. Similar to membrane filters, this technique suffers from severe clogging. Recently, the cross-flow filtration scheme was proposed to reduce the clog. ${ }^{20}$ The fluid flows tangentially rather than through the filter to minimize the clog, and to extend the 70 saturation time of the filter. In DLD, the micro-pillar arrays are patterned within a microchannel, and asymmetric bifurcation of laminar streamlines around these pillars leads to size-based deterministic paths of particles. ${ }^{15}, 16,21$ While hydrophoresis works on the microchannel with slanted obstacles patterned on 75 the top/bottom walls, a lateral pressure gradient is induced to deflect and focus microparticles along lateral flows. Although these methods have been proven effective, the risk of clogging is still a major drawback. For example, the gap of pillars in DLD is only 2 times of the critical particle size for a $1 / 6$ tilt angle ${ }^{21}$. The 
groove gap $\left(h_{g}\right)$ should be in $a<h_{g}<2 a$ for a hydrophoretic device, ${ }^{22}$ where $a$ is target particle diameter, for red blood cells, $h_{g}$ is only $\sim 8 \mu \mathrm{m}^{23}{ }^{24}$ These microchannels with such a small dimension are very prone to be blocked and paralysed by debris 5 or cell cluster. In addition, the flow rate is still low $(0.5 \sim 20 \mu \mathrm{l}$ $\left.\min ^{-1}\right){ }^{23,}{ }^{24}$ Therefore, an ideal microfluidic blood plasma extraction technique should have a large throughput, continuous manner and relatively large dimension, as well as high collection yield and purity. ${ }^{1}$

10 Inertial microfluidics is a promising technique due to its nature of high throughput, simple design and easy fabrication ${ }^{18}$. Inertial migration is an interesting phenomenon that randomly dispersed particles in the entrance of a straight channel migrate laterally to several cross sectional equilibrium positions after a long enough 15 distance. This phenomenon was first observed in a macroscaled straight channel by Segre and Silberberg in 1960s. ${ }^{25,}{ }^{26}$ Although the mechanism of this phenomenon is still not completely uncovered, two dominant forces are commonly recognized as being responsible for this phenomenon: the shear gradient lift 20 force $F_{L S}$ acting down the velocity gradient towards the channel walls due to shear rate in Poiseuille flow, and a wall-induced lift force $F_{L W}$ directed towards the centerline of the channel. Inertial migration has been widely applied in inertial microfluidics for particle focusing and separation. Mach and Di Carlo ${ }^{27}$ presented 25 a massively parallelized microfluidic device that passively separates pathogenic bacteria from diluted $(1 / 100)$ blood. The device consists of 40 single straight micro-channels placed as a radial array. Each channel consists of three different crosssections, and uses a unique differential transit time by size30 dependent inertial lift forces to obtain cell separation. A removal efficiency of $>80 \%$ pathogenic bacteria from blood has been demonstrated, with a high throughput of 400 million cells min $^{-1}$ and a flow rate of $4 \mathrm{ml} \mathrm{min}^{-1}$. Besides the removal of pathogenic bacteria from blood, the device was also claimed to be suitable 35 for blood plasma isolation, stored blood filtration, and municipal water filtration. Later, Hur et al. ${ }^{28}$ utilized differential hydrodynamic inertial lift forces between single cells and multicellular clusters in a straight microchannel to isolate adrenal cortical progenitor cells from digestions of murine adrenal 40 glands. Recently, Zhou et al. ${ }^{29}$ reported a polished cascaded straight channels to achieve a much higher separation efficiency $(\sim 99 \%)$ and purity $(\sim 90 \%)$. However, in order to provide efficient inertial lift force for successful particle focusing, channel dimension has to be restricted to satisfy $a / D_{h}>0.07,{ }^{30}$ i.e. $27 \mu \mathrm{m}$ ${ }_{45} \times 50 \mu \mathrm{m}$ (width $\times$ height) for 9.94 and $20 \mu \mathrm{m}$ particles ${ }^{29}$, and 20 $\mu \mathrm{m} \times 60 \mu \mathrm{m}$ for red blood cells, ${ }^{28}$ where $D_{h}$ is the hydraulic diameter of channel. Such a restriction of cross-section dimension leads to a high fluidic resistance, and requires more power to deliver the sample. Additionally, the channel is relatively long ${ }_{50}(>36 \mathrm{~mm})$ leading to a large device footprint.

In order to release the restriction of channel dimension, channel curvature was introduced to provide a secondary flow to assist and modify inertial focusing progress. Spiral channel that the curvature is along the same direction consistently was 55 investigated widely for particle inertial focusing, ${ }^{31,32}$ separation ${ }^{33-40}$ and cell encapsulation. ${ }^{41}$ However, the spiral design is not easy to parallelize due to its nonlinear structure, which limits its throughput. The serpentine channel, whose curvature direction alternating along a channel length, has been proposed and 60 investigated by our group ${ }^{2,4}$ as well as others. ${ }^{30,42}$ We found that a symmetric serpentine channel can provide more intriguing and useful focusing patterns. Particularly, when the center-directed centrifugal force and secondary flow drag are dominating the two-sided inertial lift forces, particles will be focused at the 65 center of channel, which has been validated experimentally and numerically. ${ }^{4}$ At a relatively low flow rate, the phenomenon of two-sided focusing was observed, and the flow rate threshold between the single-center focusing and two-sided focusing is size sensitive. The overlap of working area for these two focusing 70 patterns between different-sized particles can enable a complete separation. ${ }^{2}$ However, attention was rarely paid to the mechanism of this two-sided focusing pattern, as well as its application on blood plasma extraction. And this is the major motivation of our present work.

75 The paper is organized as follows. First, the inertial focusing in straight channel with different aspect ratios was investigated; Then, serpentine channel with a low aspect ratio $(\mathrm{AR}=0.21)$ was selected to demonstrate the enhancement of secondary flow on inertial focusing process, and mechanism of this enhancement 80 was explored; Third, the effect of particle size on the focusing performance and filtration was investigated. Subsequently, extraction of plasma in the serpentine channel was demonstrated with excellent plasma purity and high collection yield. Finally, the parallelization technology for the serpentine channel was 85 introduced, with some design consideration discussed.

\section{Theory}

\section{Inertial migration}

The inertial migration of particles in a straight channel is driven by the counteraction of two inertial effects: shear gradient lift 90 force $F_{L S}$, and wall lift force $F_{L W}$. The shear gradient lift force $F_{L S}$ depends on the curvature of fluid velocity profile, while the wall lift force $F_{L W}$ is a result of wall-induced disturbance on the flow field around the suspended particles. The existence of equilibrium positions is resulted from the balance of two inertial lift forces. ${ }_{95}$ The net inertial lift force can be expressed as following. ${ }^{18,43}$

$$
\begin{gathered}
F_{L}=\frac{\rho_{f} U_{m}^{2} a^{4}}{D_{h}^{2}} f_{L}\left(R_{C}, x_{C}\right) \\
R_{C}=\frac{\rho_{f} U_{m} D_{h}}{\mu_{f}}
\end{gathered}
$$

where $\rho_{f}, U_{m}$ and $\mu_{f}$ are fluid density, maximum velocity and dynamic viscosity, respectively. $f_{L}\left(R_{C}, x_{C}\right)$ is lift coefficient of net 100 inertial lift force, which is a function of particles position within cross-section of channel $x_{C}$ and channel Reynolds number $R_{C}{ }^{18}$. The situation where $f_{L}=0$ corresponds to the equilibrium positions of particles. At $R_{C}<100$ that is typical for most microfluidic applications, the lift coefficient remains relatively constant, and 105 can be approximated averagely as $f_{L} \approx 0.5 .{ }^{30}$ In a straight channel, particles' lateral migration velocity $\left(U_{L}\right)$ and the minimum channel length $\left(L_{m i n}\right)$, which is required for particles to migrate to their equilibrium positions, can be derived by balancing the net inertial lift force and Stokes drag. ${ }^{44}$ 


$$
\begin{gathered}
F_{s t k s}=3 \pi \mu_{f} a U_{L} \\
U_{L}=\frac{F_{L}}{3 \pi \mu_{f} a}=\frac{\rho_{f} U_{m}^{2} a^{3}}{6 \pi \mu_{f} D_{h}^{2}} \\
L_{\min } \approx \frac{D_{h}}{2 U_{L}} * U_{m}=\frac{3 \pi \mu_{f} D_{h}^{3}}{\rho_{f} U_{m} a^{3}}
\end{gathered}
$$

\section{Numerical simulation}

${ }_{5}$ In order to understand and analyse the focusing behaviour of particles, numerical simulation was employed to calculate the flow field in straight channels with different cross-sections and the designed serpentine channel. A laminar steady incompressible flow model was used to calculate the flow field. The inlet 10 condition was set with a uniform average velocity calculated from the input flow rate, and a non-slip boundary condition was applied onto the channel walls. Equations governing steady incompressible flow are:

Navier-Stokes equation:

15

$$
\rho_{f} \vec{v}_{f} \cdot \nabla \vec{v}_{f}=-\nabla P+\mu \nabla^{2} \vec{v}_{f}
$$

Continuity equation:

$$
\nabla \cdot \vec{v}_{f}=0
$$

Non-slip boundary condition:

$$
\vec{v}_{w}=0
$$

20 where $\vec{v}_{f}$ and $P$ are the velocity vector and pressure of fluid, respectively; $\vec{v}_{w}$ is fluid velocity vector at the channel walls. $\nabla$ is the Nabla operator, and $\nabla^{2}$ is the Laplace operator..

\section{Materials and Methods}

\section{Design and fabrication}

${ }_{25}$ The serpentine channel used in our experiments consists of a 15.2 $\mathrm{mm}$ serpentine section with 15 zigzag periods. The depth of the channel is uniform at $42 \mu \mathrm{m}$. The length and width of each U-turn are both $700 \mu \mathrm{m}$. The width of micro-channel is $200 \mu \mathrm{m}$. A trifurcating outlet at the end of the channel is implemented at the 30 end of serpentine channel. The two-sided symmetrical bifurcations are combined together as a single outlet to simplify collection. In order to investigate the effects of channel aspect ratio and dimension on the inertial focusing, straight microchannels with different cross-sections of $50 \mu \mathrm{m} \times 42 \mu \mathrm{m}$ (width $\times$

35 depth), $100 \mu \mathrm{m} \times 42 \mu \mathrm{m}$ and $200 \mu \mathrm{m} \times 42 \mu \mathrm{m}$ were fabricated respectively. All devices were fabricated by standard photolithography and PDMS soft lithography techniques. ${ }^{45}$

\section{Particle and cell preparation}

Internally dyed fluorescent polystyrene particles with diameters 40 of $3 \mu \mathrm{m}$ (Thermo Fisher Scientific, Product No. R0300, CV5\%), $5 \mu \mathrm{m}$ (Product No. G0500, CV5\%) and $10 \mu \mathrm{m}$ (Product No. G1000, CV5\%) were suspended respectively in deionized (DI) water with $0.025 \% \mathrm{w} / \mathrm{w}$. Tween 20 (SIGMA-ALDRICH Product No. P9416) with $0.1 \% \mathrm{w} / \mathrm{v}$ was added to prevent the particles
45 from aggregation. These beads were used as a preliminary and simple model of blood cells, as they have similar dimensions and densities $\left(\rho_{\text {polystyrene beads }}=1.05 \mathrm{~g} \mathrm{~cm}^{-3}, 1.04<\rho_{\text {blood cells }}<1.09 \mathrm{~g} \mathrm{~cm}^{-3}\right)$, but they cannot reflect the ellipsoid geometry and deformability of red blood cells. ${ }^{46}$ The human whole blood was taken from ${ }_{50}$ healthy adult male volunteers with a vacutainer tube (Vacuette) containing anticoagulant agent lithium heparin. The blood sample was diluted with phosphate-buffered saline (PBS) by 1/5 1/20 before pumped into the microfluidic device.

\section{Experimental setup and method}

55 The microfluidic device was placed on an inverted microscope (CKX41, Olympus, Japan), illuminated by a mercury arc lamp. Particle suspension was pumped by a syringe pump (Legato 100, Kd Scientific). The fluorescence images were observed and captured by a CCD camera (Rolera Bolt, Q-imaging, Australia), 60 and then post-processed and analysed using the software QCapture Pro 7 (Q-imaging, Australia). The exposure time for each frame was consistently $100 \mathrm{~ms}$. The particle and cell concentrations were measured by a haemocytometer.

\section{Results and Discussions}

\section{${ }_{65}$ Inertial focusing in a straight channel}

Inertial migration becomes apparent when $a / D_{h}>0.07$ and $R_{p} \sim$ $1 .^{30}$ The number and position of the particle inertial equilibrium position depend mainly on the geometry of the channel and flow Reynolds number. In the straight channel with an aspect ratio $70(\mathrm{AR}=$ depth/width $) \sim 1$ as shown in Fig. 1a, there are four equilibrium positions, facing the centre of each channel surface. Increasing the channel width with the channel depth constant, when $\mathrm{AR}$ is between $1 / 3$ and $1 / 2$, the equilibrium positions are reduced to two, due to the blunted velocity profile along the 75 channel width and corresponding reduction in shear gradient lift force. ${ }^{47}$ Two equilibrium positions are located at the centre of channel width, facing the top and bottom walls (Fig. 1b). However, when the AR is reduced to $1 / 5$, as the inertial lift force is very weak along the channel width, it was hard to observe 80 distinct equilibrium positions (Fig. 1c). In addition, when inertial focusing has been achieved completely, the inertial equilibrium positions (fluorescent streaks) are almost steady with varying Reynolds numbers in the tested area. According to Eq. 5, for the straight channel with a cross-section of $200 \mu \mathrm{m} \times 42 \mu \mathrm{m}$, under an 85 average flow velocity of $0.7 \mathrm{~m} \mathrm{~s}^{-1}\left(R_{C}=70\right)$, the minimum channel length for $10-\mu \mathrm{m}$ particles to migrate to their equilibrium positions is about $70 \mathrm{~mm}$. While in the experiments, successful focusing has not been obtained after $70 \mathrm{~mm}$. The main reason for this inconsistency is that the size ratio of particle to channel ${ }_{90} \mathrm{a} / W=0.05$ does not meet the minimum requirement of $0.07 .^{30} \mathrm{This}$ can also be explained by the shape of velocity profile along the channel width. With the decreasing aspect ratio, velocity distribution along the width becomes increasingly flat (Fig. 1d). In the channel with $\mathrm{AR}=0.21(200 \mu \mathrm{m} \times 42 \mu \mathrm{m})$, the fluid shear ${ }_{95}$ rate $\dot{\gamma}(=d u / d x)$ is very small $(\sim 0)$ along a large central area ($0.3 W \leq x \leq 0.3 W$ ). As the inertial lift force $F_{L}$ is proportional to $i^{2},{ }^{43}$ it is very small within this central area in this small AR channel, causing very slow even no inertial migration speed of particles along the width direction. Therefore, a lot of particles 100 still occupy the channel central area even after $70 \mathrm{~mm}$ in the 
channel with $\mathrm{AR}=0.21$ (Fig. 1c(I)). While along the depth direction, the velocity profile maintains as parabolic shape, although the maximum magnitude of velocity shows a slightly decreasing trend with the aspect ratio. So it is expected that two 5 equilibrium positions along depth direction still exist.

\section{Secondary flow aided inertial focusing in a serpentine channel}

In order to demonstrate the enhancement of curvature on inertial focusing, the cross-section dimension of serpentine channel was set to $200 \mu \mathrm{m} \times 42 \mu \mathrm{m}$, where even $10-\mu \mathrm{m}$ particles cannot achieve 10 adequate focusing in a straight channel with this cross-section as we demonstrated above, let alone smaller particles.

When the particles were pumped into the serpentine microchannel, they randomly distributed at the inlet, represented by four different coloured particles in Fig. 2a, occupying four 15 characteristic positions within micro-channel: two (purple and green dots) are near wall regions where the net inertial lift force is directing towards channel centre, and another two (red and blue dots) are near channel centre where inertial lift force is pointing to channel walls. Due to the large secondary flow drag and 20 centrifugal force in the alternating turns, as well as the same effect of inertial lift force (Fig. 2b), the particles near channel walls (purple and green dots) rapidly migrated to the final equilibrium positions. While for the particles within the channel central area (red and blue dots), the direction of secondary flow 25 drag varies along streamlines, in some positions it assists inertial lift force to accelerate particles to the equilibrium positions, in other positions it competes against inertial lift force to disturb particles from their equilibrium positions. Although the secondary flow drag is larger than the inertial lift force within the 30 central area where shear rate $\dot{\gamma} \approx 0$, near the inertial equilibrium positions, the inertial lift force can still dominate the secondary flow due to the large shear rate $\dot{\gamma}$. The final effect is that the secondary flow is sweeping particles towards two-sided walls, facilitating migration of particles towards the inertial equilibrium 35 positions (Fig. 2b). However, in the straight channel without the assistance of secondary flow, particles cannot reach the inertial equilibrium positions due to the very weak inertial lift force alone within the central area (Fig. 1c). This is the reason why the introduction of curvature can promote the particle inertial 40 migration and focusing. It should be noted that the above analysis is based on the assumption that final equilibrium positions are the theoretical inertial equilibrium positions in a Poiseuille flow: 0.3 times diameter from channel center. In the actual situation, the final trajectory of particles is a little different due to the 45 rectangular cross-section and channel curvature, as shown in Fig. 2c. Fig. $2 \mathrm{~d}$ shows the fluorescent trajectory of $10-\mu \mathrm{m}$ particles under different periods within a serpentine channel. Fluorescent light near channel walls disappear promptly after about three periods, while fluorescent light within channel central area 50 weakens gradually and vanishes after more than ten periods. This indicates that the particles near two-sided walls migrate much faster to the equilibrium positions than their counterparts near the channel centre, which again validates above analysis.

\section{Effects of particle size}

${ }_{55}$ The cellular components of blood range in size from 7 to $15 \mu \mathrm{m}$ for spherical leukocytes (WBCs), to $6-8 \mu \mathrm{m} \times 2 \mu \mathrm{m}$ for discoid RBCs, while platelets are between 2 and $4 \mu \mathrm{m}$ in diameter. The concentration of blood cells are $\sim 5 \times 10^{9} \mathrm{RBCs} \mathrm{ml}^{-1},(2-5) \times 10^{8}$ platelets $\mathrm{ml}^{-1}$, and $(5-10) \times 10^{6} \mathrm{WBCs} \mathrm{ml}^{-1}$. ${ }^{48}$ Since the RBCs 60 account for $98 \%$ of blood cells, the filtration of blood cells normally focuses on the RBCs. RBCs are not perfectly spherical but discoid, their characteristic size is hard to determine. It was reported that they behave similarly as $\sim 4-\mu \mathrm{m}$ spherical particles. $^{49}$

65 Before the filtration of human whole blood, inertial focusing of different-sized particles in a serpentine was investigated. The fluorescent images and their corresponding fluorescent profiles within different positions were plotted in Fig. 3. It is found that inertial focusing of 10 - $\mu \mathrm{m}$ particles was efficiently obtained after $7010^{\text {th }}$ period, with an effective length of $10 \mathrm{~mm}$. Even stretching the serpentine to a straight line, the effective length is only 20 $\mathrm{mm}$. This is far less than the $70 \mathrm{~mm}$ straight channel, in which $10-\mu \mathrm{m}$ particles still cannot achieve successful focusing. There are three particle-free areas at the outlet, located at $0 \sim 37.25 \mu \mathrm{m}$, ${ }_{75} 58.25 \sim 140.85 \mu \mathrm{m}$ and 162.35 200 $\mu \mathrm{m}$ respectively, occupying $\sim 78.75 \%$ channel width. While for smaller particles, these particle-free areas are decreased to $66.25 \%$ for $5-\mu \mathrm{m}$ beads and $33.2 \%$ for $3-\mu \mathrm{m}$ beads. Smaller particles cannot focus as tight as larger ones, because the inertial lift force and secondary flow drag 80 are both proportional to the particle size.

The evaluation of inertial focusing performance of differentsized particles in the serpentine channel confirmed that there are basic three particle free regions at the channel outlet, which can be utilized for extracting plasma (Fig. 4a). Here, the central 85 particle free region was selected since it occupies much more plasma flow rate than the other two areas (Fig. 4b), therefore a trifurcation outlet system was implemented at the end of serpentine channel. Three kinds of polystyrene beads were pumped through the device. The concentrations of particles 90 before and after filtration were plotted in Fig. 4c. An average filtration efficiency of more than $99 \%$ was obtained after a single process, which is higher than most of previous passive devices. ${ }^{49-}$ 52

\section{Extraction of blood plasma}

95 The blood sample was taken from a healthy adult male volunteer, and it was contained within a vacutainer tube (Vacuette) containing anticoagulant agent lithium heparin. The blood sample was diluted by 20 times with phosphate-buffered saline (PBS) before pumped into the microfluidic device with a flow rate of $100350 \mu \mathrm{min}^{-1}$. The blood plasma was extracted from the central branch of bifurcation, as schematically illustrated in Fig. 5a. From the bright-field image of blood cells inertial focusing at the outlet (Fig. 5b), we can clearly see that there were two blood cell focusing streaks (two sided black streaks). This is within our 105 expectation according to the primary tests with polystyrene beads. Two series filtrations were conducted in the same device, and the blood cell concentrations before and after filtration were plotted in Fig. 5c. More than 99.75\% blood cells were removed after the first process, with a further improvement of rejection 110 ratio $>99.95 \%$ achieved by the second process. The average depletion capacity of $\sim 10^{2}$ blood cells was provided in each process. Additionally, the plasma collection yield was as high as $46 \%$. The images of the working device, two collections and original blood sample (Fig. 5d) demonstrate the excellent 115 filtration capacity of our device. 
Besides, the effect of haematocrit (Hct) on the inertial focusing in serpentine channel was investigated. Haematocrit, also known as erythrocyte volume fraction (EVF), is the volume percentage (\%) of red blood cells in blood. It is normally about $45 \%$ for men 5 and $40 \%$ for women. The whole blood sample was diluted by $1 / 5$, $1 / 10$, and $1 / 20$ with PBS respectively. And the corresponding Hct are $9.0 \%, 4.5 \%$ and $2.25 \%$, respectively. Pumping these samples into the device, bright field images at the end of serpentine channel and bifurcation were shown in Fig. 6a. And the bright 10 field intensity profile along the channel width was plotted in Fig. 6b. Increasing Hct, the width of cells focusing streaks expands, and the area of cell-free region reduces. When Hct $\geq 9.0 \%$, cells almost occupy the whole channel width, which is impossible to collect cell-free plasma under this situation. This can be 15 explained by the obvious cell-cell interaction in blood sample with such high concentration $\left(\sim 1 \times 10^{9}\right.$ cells $\left.\mathrm{ml}^{-1}\right)$, which deteriorates cell focusing performance. This is actually one main limitation of inertial microfluidics.

\section{Parallelization technology}

20 In inertial microfluidics device, particle-particle interaction always requires to be reduced by the dilution of blood sample, in order to prevent the deterioration of inertial focusing and separation performance. The dilution actually reduces the net throughput of device, although the volumetric flow rate of inertial 25 microfluidic is very high. In order to improve the throughput to the scale of conventional device, i.e. macroscale centrifugation with a throughput of $\sim \mathrm{ml} / \mathrm{min}$, a parallelization technology is needed. Parallelization design can be along the vertical direction or planar direction. On vertical direction, device is stacked by 30 many layers to amplify the throughput of the whole device by the number of layers, ${ }^{23}$ however it faces challenges of hard implementation of uniform input condition for each layers, which is critical for inertial microfluidic device. On planar direction, the whole throughput is determined by the number of parallel 35 channels, and the channel with linear geometry is always preferred, i.e. straight, expansion-contraction or serpentine. Here, we designed and fabricated a device with 8 parallel serpentine channels along the planar direction (Fig. 7a, b). A symmetric design for the inlet and outlet sections was implemented to ensure 40 that input and outlet conditions for all the serpentine channels are uniform, so that their flow fields and stream splitting at bifurcations are the same. Base on the Hagen-Poiseuille's law, the network of microfluidic channel can be described by electric circuit analogy, ${ }^{53}$ as shown in Fig. 7c. The flow rate in each ${ }_{45}$ branch of bifurcation is expressed as:

$$
Q_{4}=\left(P_{i n}-Q_{0} R_{0}-\frac{Q_{0}}{2} R_{1}-\frac{Q_{0}}{4} R_{2}-\frac{Q_{0}}{8} R_{3}-P_{0}\right) /\left(R_{4}+16 R_{12}+8 R_{11}+4 R_{9}+2 R_{7}\right)
$$

$$
Q_{5}=\left(P_{i n}-Q_{0} R_{0}-\frac{Q_{0}}{2} R_{1}-\frac{Q_{0}}{4} R_{2}-\frac{Q_{0}}{8} R_{3}-P_{0}\right) /\left(R_{5}+8 R_{10}+4 R_{8}+2 R_{6}\right)
$$

$\frac{Q_{5}}{Q_{4}}=\frac{R_{4}+16 R_{12}+8 R_{11}+4 R_{9}+2 R_{7}}{R_{5}+8 R_{10}+4 R_{8}+2 R_{6}}=\frac{\frac{R_{4}}{R_{5}}+16 \frac{R_{12}}{R_{5}}+8 \frac{R_{11}}{R_{5}}+4 \frac{R_{9}}{R_{5}}+2 \frac{R_{7}}{R_{5}}}{1+8 \frac{R_{10}}{R_{5}}+4 \frac{R_{8}}{R_{5}}+2 \frac{R_{6}}{R_{5}}}$

When $R_{6-12} \ll R_{4,5}$, then $Q_{5} / Q_{4} \approx R_{4} / R_{5}$. The hydraulic resistance $R_{H}=C_{\text {geometry }} \mu L / A^{2}$, where $C_{\text {geometry }}$ is the geometric ${ }_{55}$ coefficient, $L$ is the channel length and $A$ is the area of channel cross-section. ${ }^{53}$

In order to make the assumption $R_{6-12}<<R_{4,5}$ valid, the following design considerations were adopted: (i) The connecting channel sections corresponding to $R_{6-12}$ should have a large width 60 and short length as much as possible, to reduce the corresponding hydraulic resistances; (ii) In order to obtain a relatively large resistance for $R_{4,5}$, the micro-channels representing $R_{4,5}$ should be much narrower with longer length. The micro-channel section corresponding to $R_{5}$ was even designed as a serpentine structure 65 to further increase its resistance. After that, computational costs (time and space) can be reduced significantly, and only one bifurcation outlet unit is needed for the simulation of flow field, to optimize the splitting of streamlines, as shown in Fig. 7d. The whole device was tested with diluted whole blood at a flow rate 70 of $2.8 \mathrm{ml} \mathrm{min}^{-1}$, with a high throughput of $\sim 7 \times 10^{8}$ cells $\mathrm{min}^{-1}$. The parallel device can work very well under such a high flow rate (See Movie 1). The uniform cells two sided focusing and streamline bifurcation (Supplementary Fig. S1) at each serpentine channel demonstrate the feasibility of our design consideration.

\section{${ }_{75}$ Conclusions}

We reported a continuous, passive high-throughput filtration device, employing secondary flow aided inertial migration of particles in a serpentine channel. The mechanism of inertial focusing enhancement by the introduction of curvature was 80 analysed. The effects of particle size and haematocrit on the inertial focusing performance were investigated experimentally. Diluted whole blood was processed by the proposed device, with $\sim 100 \%$ blood cells removed. The collection yield of plasma was as high as $46 \%$. We also explored the parallelization design of the 85 serpentine channel for processing a large volume of samples. The fabricated device with eight parallel serpentine channels can process $\sim 7 \times 10^{8}$ cells $\mathrm{min}^{-1}$. Due to its nature of simple design, easy fabrication, continuous manner and high throughput, the proposed device can not only be a good alternative for 90 conventional device working standalone, but also easily be integrated with other components in the same device to form a sample-to-answer system.

\section{Acknowledgement}

This work was partially supported by the University of ${ }_{95}$ Wollongong through a UIC grant and China Scholarship Council. Authors thank Ms. Aleta Pupovac and Dr Ronald Sluyter for the technical assistance for blood extraction.

\section{Notes}


${ }^{a}$ School of Mechanical, Materials and Mechatronic Engineering, University of Wollongong, Wollongong, NSW 2522, Australia. Fax: +612 4221 3238; Tel: +61 24221 3490; E-mail:weihuali@uow.edu.au

${ }^{b}$ Queensland Micro- and Nanotechnology Centre, Griffith University, 5 Brisbane QLD 4111, Australia. Fax: +61 07373 58021; Tel: +61 (07) 373 53921; E-mail:nam-trung.nguyen@griffith.edu.au

$\dagger$ Electronic Supplementary Information (ESI) available: Supplementary Fig. S1 illustrates uniform streamline splitting and blood cells filtration at each outlet in the designed paralell device. Movie 1 shows actual working 10 process of parallel device under high flow rate. See DOI: $10.1039 / \mathrm{b} 000000 \mathrm{x} /$

\section{References}

1. M. Kersaudy-Kerhoas and E. Sollier, Lab Chip, 2013, 13, 3323-3346.

2. J. Zhang, S. Yan, R. Sluyter, W. Li, G. Alici and N.-T. Nguyen, Sci. 15 Rep., 2014, 4, 1-9.

3. A. A. S. Bhagat, H. Bow, H. W. Hou, S. J. Tan, J. Han and C. T. Lim, Medical \& biological engineering \& computing, 2010, 48, 9991014.

4. J. Zhang, W. Li, M. Li, G. Alici and N.-T. Nguyen, Microfluid. 20 Nanofluid., 2013, 1-12.

5. J. Tice, Ph.D., University of Illinois at Urbana-Champaign, 2013.

6. N. T. Nguyen and Z. Wu, J. Micromech. Microeng., 2005, 15, R1R16.

7. A. Y. Fu, C. Spence, A. Scherer, F. H. Arnold and S. R. Quake, Nat. 25 Biotechnol., 1999, 17, 1109-1111.

8. M. Rosenauer and M. Vellekoop, Biomicrofluid, 2010, 4, 1-12.

9. G. Késmárky, P. Kenyeres, M. Rábai and K. Tóth, Clin Hemorheol Micro., 2008, 39, 243-246.

10. Y. Nakashima, S. Hata and T. Yasuda, Sens. Actuators, B, 2010, 145, $30 \quad 561-569$.

11. J. Jung and K.-H. Han, Appl. Phys. Lett., 2008, 93, 223902.

12. M. Sun, Z. S. Khan and S. A. Vanapalli, Lab Chip, 2012, 12, 52255230.

13. J. Moorthy and D. J. Beebe, Lab Chip, 2003, 3, 62-66.

35 14. D.-S. Lee, Y. H. Choi, Y. D. Han, H. C. Yoon, S. Shoji and M. Y. Jung, ETRI Journal, 2012, 34, 226-234.

15. D. W. Inglis, J. A. Davis, R. H. Austin and J. C. Sturm, Lab Chip, 2006, 6, 655-658.

16. L. R. Huang, E. C. Cox, R. H. Austin and J. C. Sturm, Science, 2004, 304, 987-990.

17. S. Choi and J.-K. Park, Lab Chip, 2007, 7, 890-897.

18. D. Di Carlo, Lab Chip, 2009, 9, 3038-3046.

19. X.-B. Zhang, Z.-Q. Wu, K. Wang, J. Zhu, J.-J. Xu, X.-H. Xia and H.Y. Chen, Anal. Chem., 2012, 84, 3780-3786.

${ }_{45}$ 20. K. Aran, A. Fok, L. A. Sasso, N. Kamdar, Y. Guan, Q. Sun, A. Ündar and J. D. Zahn, Lab Chip, 2011, 11, 2858-2868.

21. K. Loutherback, K. S. Chou, J. Newman, J. Puchalla, R. H. Austin and J. C. Sturm, Microfluid. Nanofluid., 2010, 9, 1143-1149.

22. S. Choi, S. Song, C. Choi and J.-K. Park, Anal. Chem., 2008, 81, 5055.

23. S. Choi, T. Ku, S. Song, C. Choi and J.-K. Park, Lab Chip, 2011, 11, 413-418.

24. S. Choi, S. Song, C. Choi and J.-K. Park, Lab Chip, 2007, 7, 15321538 .
55 25. G. Segre, Nature, 1961, 189, 209-210.

26. G. Segre and A. Silberberg, J. Fluid Mech., 1962, 14, 136-157.

27. A. J. Mach and D. Di Carlo, Biotechnol. Bioeng., 2010, 107, 302311.

28. S. C. Hur, T. Z. Brinckerhoff, C. M. Walthers, J. C. Dunn and D. Di 60 Carlo, PLoS One, 2012, 7, e46550.

29. J. Zhou, P. V. Giridhar, S. Kasper and I. Papautsky, Lab Chip, 2013, 13, 1919-1929.

30. D. Di Carlo, D. Irimia, R. G. Tompkins and M. Toner, Proc. Natl. Acad. Sci. U.S.A., 2007, 104, 18892-18897.

65 31. J. M. Martel and M. Toner, Phys. Fluids, 2012, 24, 1-13.

32. N. Xiang, K. Chen, D. Sun, S. Wang, H. Yi and Z. Ni, Microfluid. Nanofluid., 2013, 14, 89-99.

33. A. A. S. Bhagat, S. S. Kuntaegowdanahalli and I. Papautsky, Lab Chip, 2008, 8, 1906-1914.

70 34. S. S. Kuntaegowdanahalli, A. A. S. Bhagat, G. Kumar and I. Papautsky, Lab Chip, 2009, 9, 2973-2980.

35. D. H. Yoon, J. B. Ha, Y. K. Bahk, T. Arakawa, S. Shoji and J. S. Go, Lab Chip, 2008, 9, 87-90.

36. J. Sun, M. Li, C. Liu, Y. Zhang, D. Liu, W. Liu, G. Hu and X. Jiang, Lab Chip, 2012, 12, 3952-3960.

37. J. Sun, C. Liu, M. Li, J. Wang, Y. Xianyu, G. Hu and X. Jiang, Biomicrofluid, 2013, 7, 011802.

38. H. W. Hou, M. E. Warkiani, B. L. Khoo, Z. R. Li, R. A. Soo, D. S.W. Tan, W.-T. Lim, J. Han, A. A. S. Bhagat and C. T. Lim, Sci. Rep., 2013, 3, 1-8.

39. G. Guan, L. Wu, A. A. Bhagat, Z. Li, P. C. Chen, S. Chao, C. J. Ong and J. Han, Sci. Rep., 2013, 3, 1-9.

40. M. E. Warkiani, G. Guan, K. B. Luan, W. C. Lee, A. A. S. Bhagat, P. K. Chaudhuri, D. S.-W. Tan, W. T. Lim, S. C. Lee and P. C. Chen, Lab Chip, 2014, 14, 128-137.

41. I. Vermes, D. A. Weitz and A. van den Berg, Lab Chip, 2012, 12, 2881-2887.

42. D. Di Carlo, F. Jon, D. Irimia, R. G. Tompkins and M. Toner, Anal. Chem., 2008, 80, 2204-2211.

90 43. E. S. ASMOLOV, J. Fluid Mech., 1999, 381, 63-87.

44. A. A. S. Bhagat, S. S. Kuntaegowdanahalli and I. Papautsky, Microfluid. Nanofluid., 2009, 7, 217-226.

45. D. C. Duffy, J. C. McDonald, O. J. A. Schueller and G. M. Whitesides, Anal. Chem., 1998, 70, 4974-4984.

95 46. D. Di Carlo, J. F. Edd, D. Irimia, R. G. Tompkins and M. Toner, Anal. Chem., 2008, 80, 2204-2211.

47. A. J. Chung, D. R. Gossett and D. Di Carlo, Small, 2013, 9, 685-690.

48. M. Toner and D. Irimia, Annu. Rev. Biomed. Eng., 2005, 7, 77-103.

49. M. G. Lee, S. Choi, H. J. Kim, H. K. Lim, J. H. Kim, N. Huh and J. $100 \quad$ K. Park, Appl. Phys. Lett., 2011, 98, 1-3.

50. M. G. Lee, J. H. Shin, S. Choi and J.-K. Park, Sens. Actuators, B, 2014, 190, 311-317.

51. A. I. Rodríguez-Villarreal, M. Arundell, M. Carmona and J. Samitier, Lab Chip, 2010, 10, 211-219.

105 52. M. Kersaudy-Kerhoas, R. Dhariwal, M. P. Desmulliez and L. Jouvet, Microfluid. Nanofluid., 2010, 8, 105-114.

53. K. W. Oh, K. Lee, B. Ahn and E. P. Furlani, Lab Chip, 2012, 12, 515-545. 
(a)

(I)

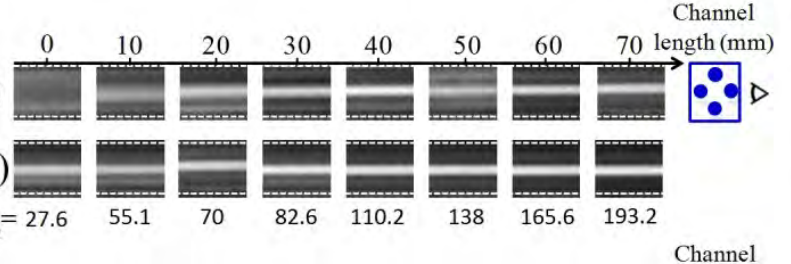

(b)

(I)

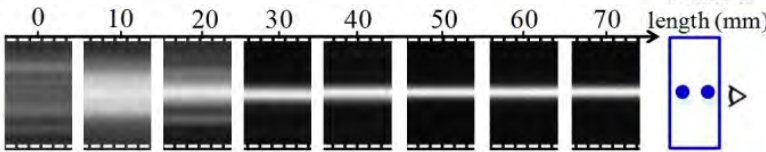

(II)
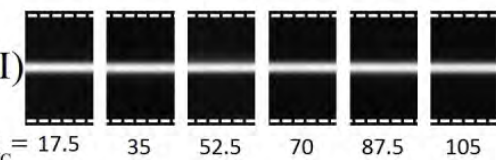

(c)

(I)

$\begin{array}{llllll}0 & 10 & 20 & 30 & 40 & 50\end{array}$
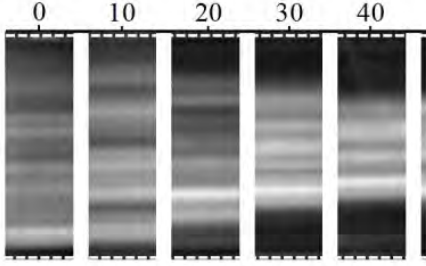

50

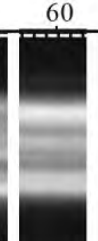

70 length $(\mathrm{mm})$
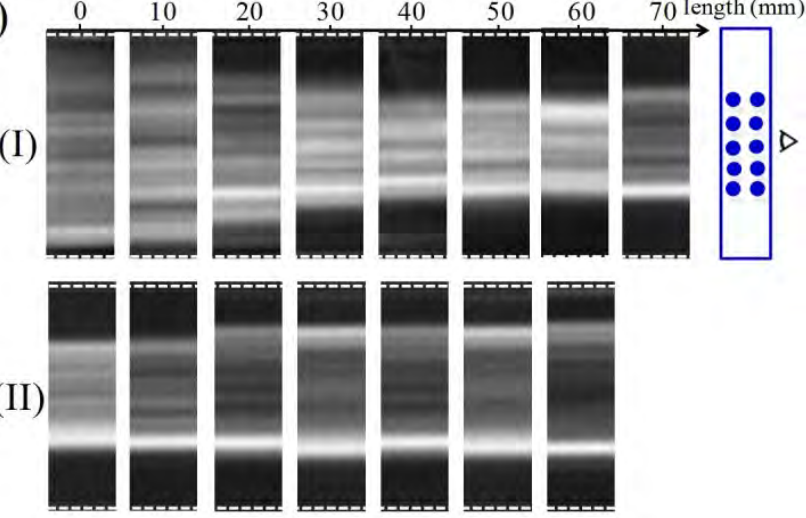

$R_{C}=50$

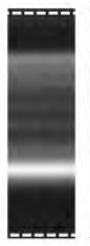

90

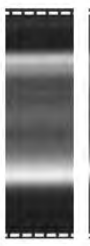

$110 \quad 130$

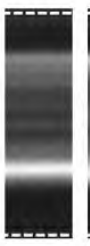

$30 \quad 150$

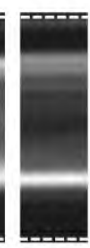

170 (d)

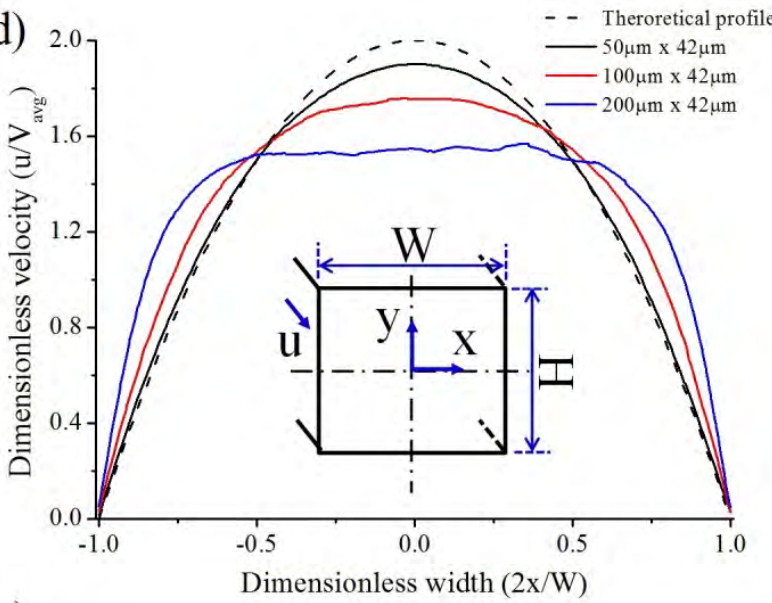

(e)

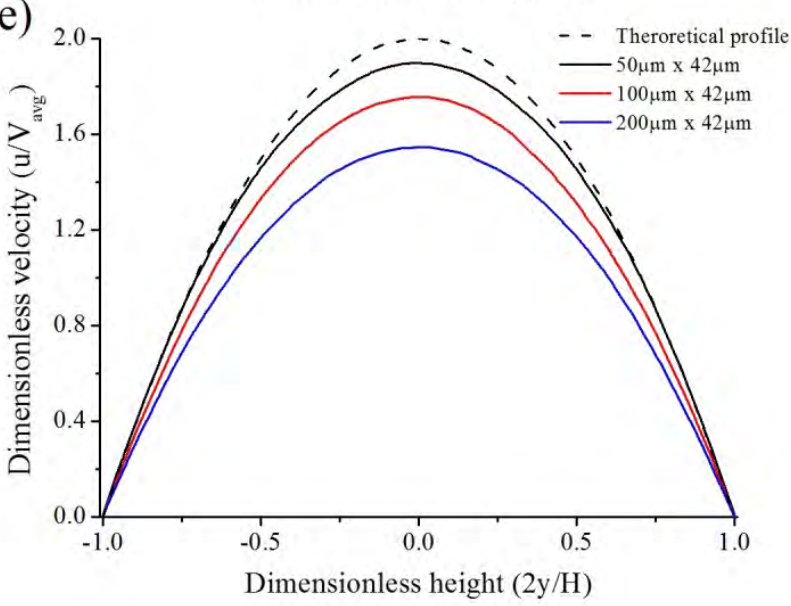

Fig. 1 Inertial focusing phenomenon in a straight channel with cross sections of (width $\times$ height) of (a) $50 \mu \mathrm{m} \times 42 \mu \mathrm{m}, A R=0.84$; (b) $100 \mu \mathrm{m} \times 42 \mu \mathrm{m}$, $A R=0.42$; and (c) $200 \mu \mathrm{m} \times 42 \mu \mathrm{m}, A R=0.21$. (I) The inertial focusing at different channel positions when $R_{c}=70$; and (II) The inertial focusing under different channel Reynolds number after the same channel length of $70 \mathrm{~mm}$. (d) Simulated velocity profiles along the channel width for straight

5 channels with different cross-sections. Velocity distribution is evaluated along the center-plane $y=0$. (e) Velocity profiles along the channel depth for straight channels with different cross-sections. Velocity distribution is evaluated along the center-plane $\mathrm{x}=0$. Velocity is normalized by input average velocity $\mathrm{V}_{\text {avg. }}$. 
(a)

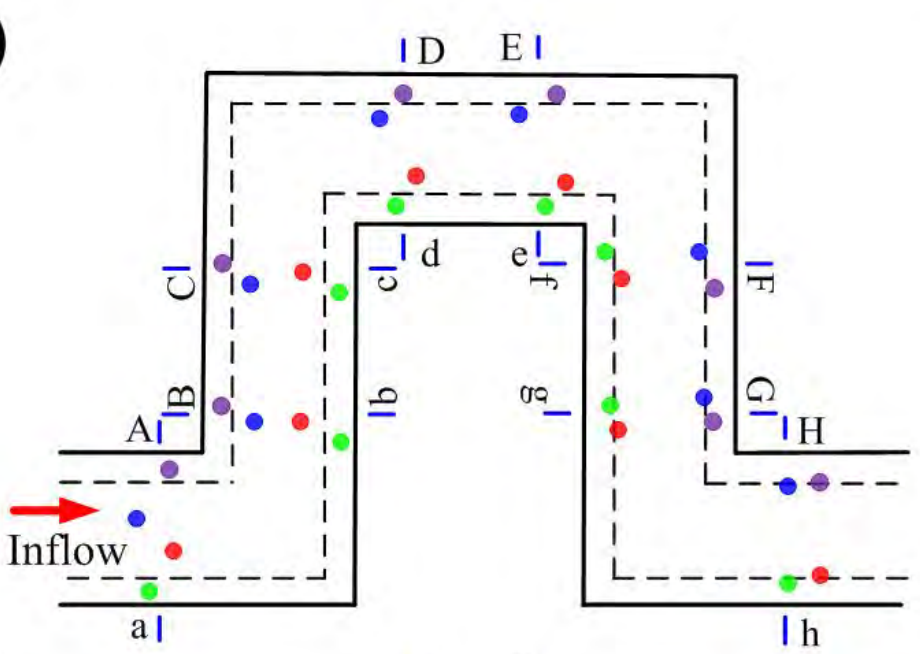

(c)

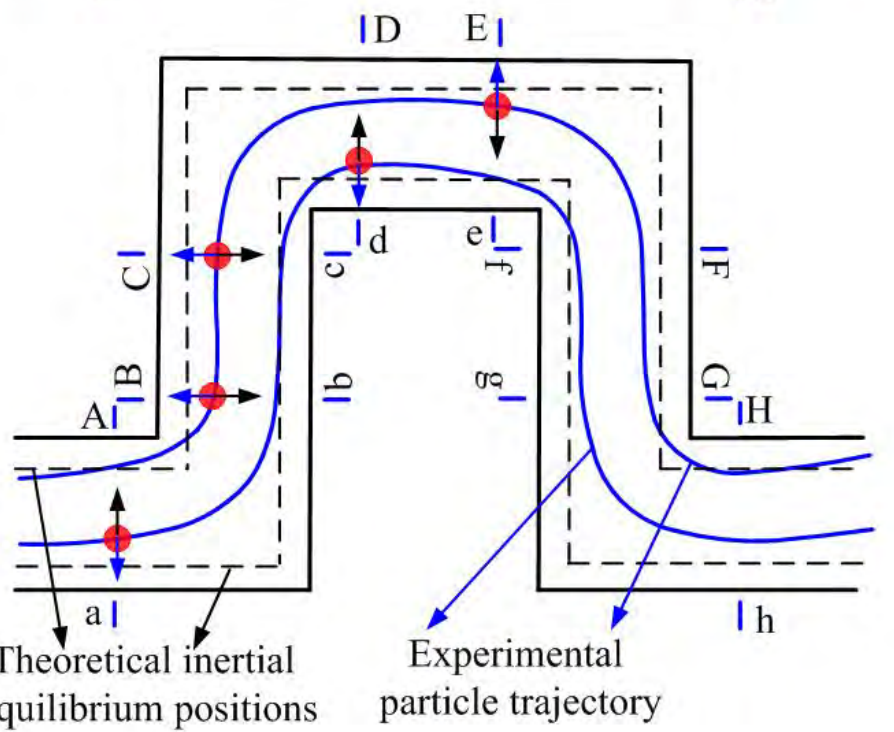

(b)

Theoretical inertial
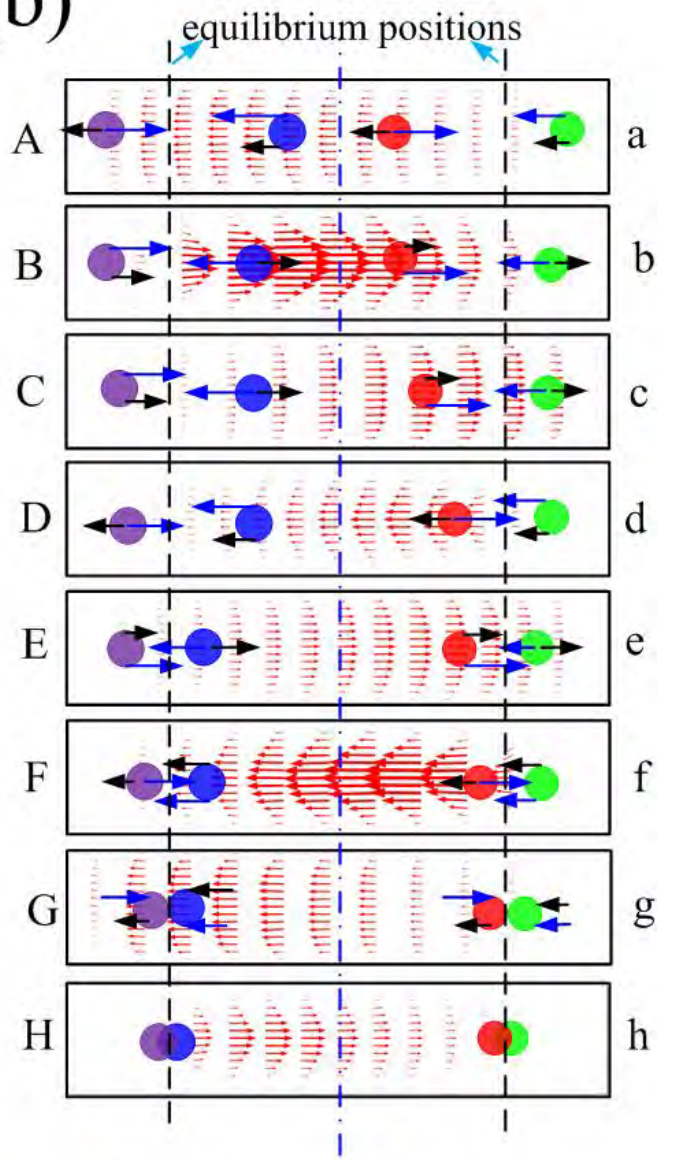

$\leftarrow$ Inertial lift force $F_{L}$ Secondary flow drag $F_{D}$

(d)
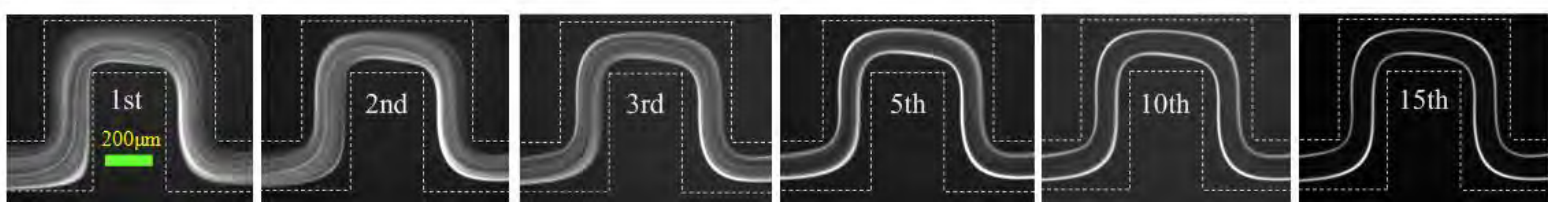

Fig. 2 Mechanism of secondary flow-aided inertial focusing in a serpentine channel. (a) Schematic illustration of particle inertial focusing process in a serpentine channel. (b) Dynamic analysis of particles within eight typical cross-sections under the influence of secondary flow. (c) The theoretical inertial equilibrium positions and the experimental particle trajectory. (d) The fluorescent images of particle trajectory in different zigzag periods of a serpentine 5 channel. 
a

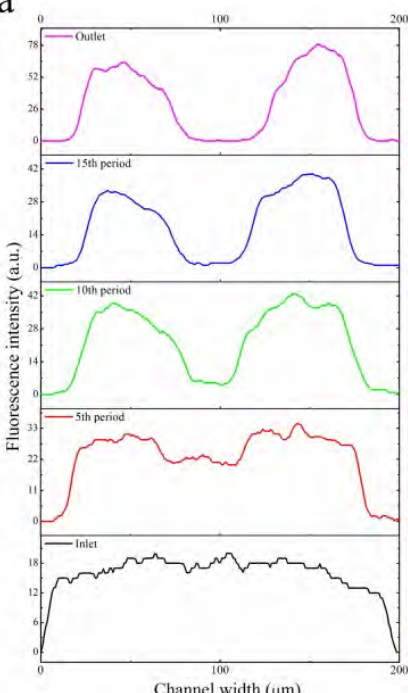

(I) b

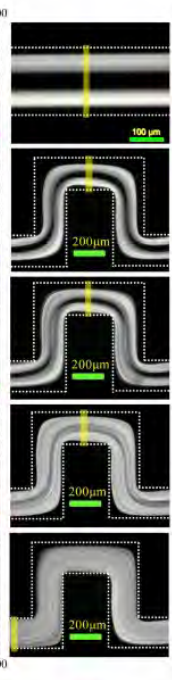

(II)

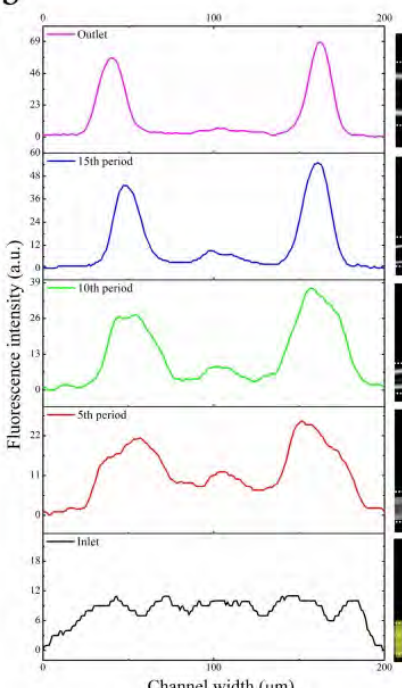

(I)

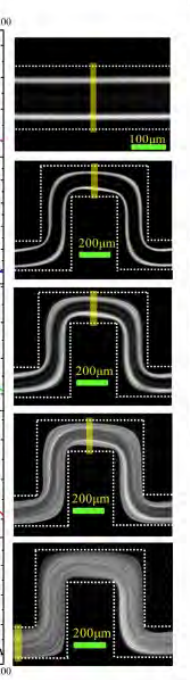

(II)

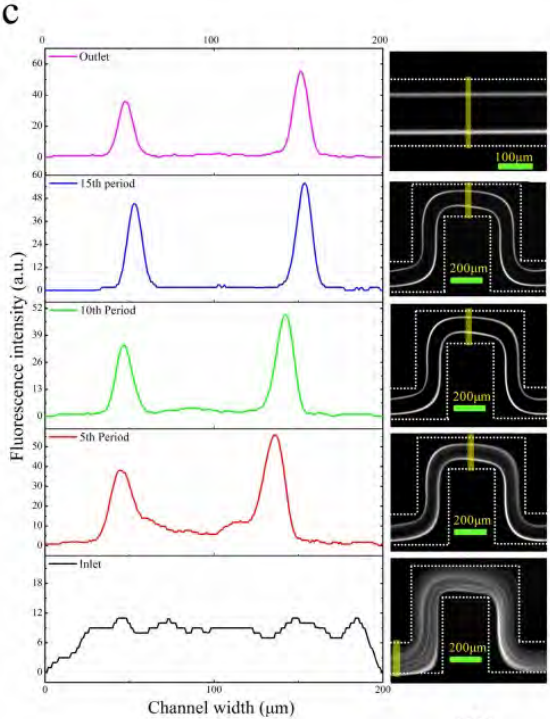

(I)

(II)

Fig. 3 Two sided inertial focusing in a serpentine channel for different-sized particles: (a) 3- $\mu \mathrm{m}$ (b) 5- $\mu \mathrm{m}$ and (c) 10- $\mu \mathrm{m}$ in diameter. (I) Fluorescent intensity profile and (II) their corresponding fluorescent images at different zigzag periods. 


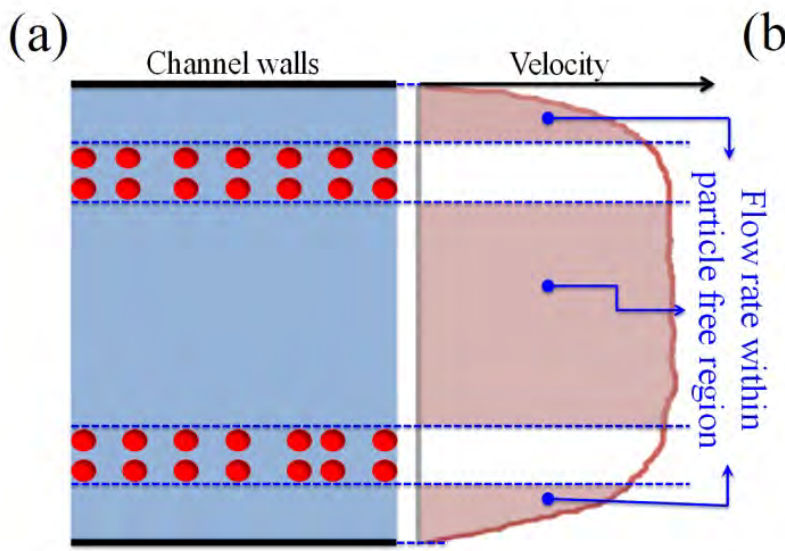

(c)

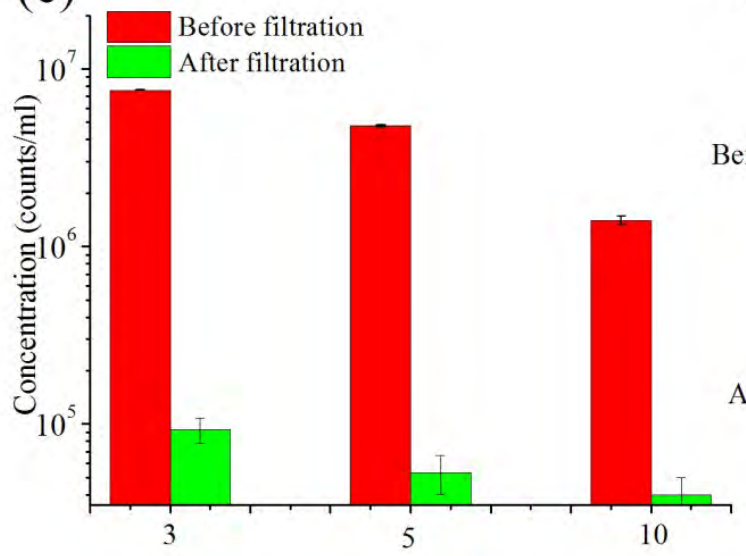

(d)

(b) $0.8-$ Two sided particle free regions
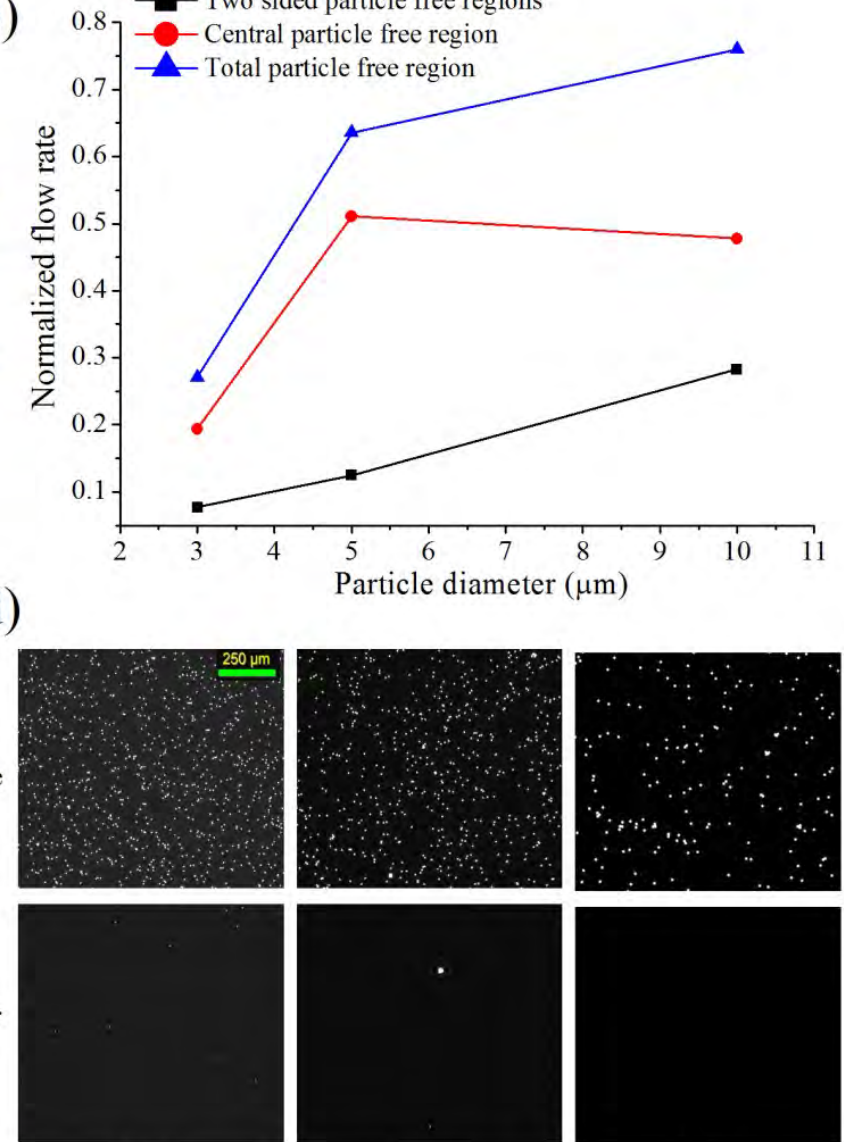

$3 \mu \mathrm{m}$

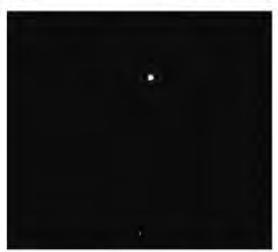

$5 \mu \mathrm{m}$

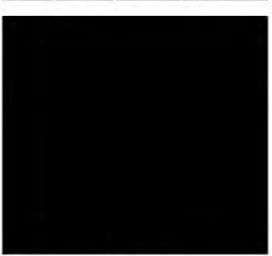

$10 \mu \mathrm{m}$

Fig. 4 (a) Three particle-free regions at the channel outlet, and their corresponding flow rates. (b) The normalized fluid flow rate within particle free regions for different-sized particles. (c) The concentrations of 3- $\mu \mathrm{m}, 5-\mu \mathrm{m}$ and $10-\mu \mathrm{m}$ polystyrene beads before and after a single filtration process, and (d) their corresponding fluorescent images in a hemocytometer. 


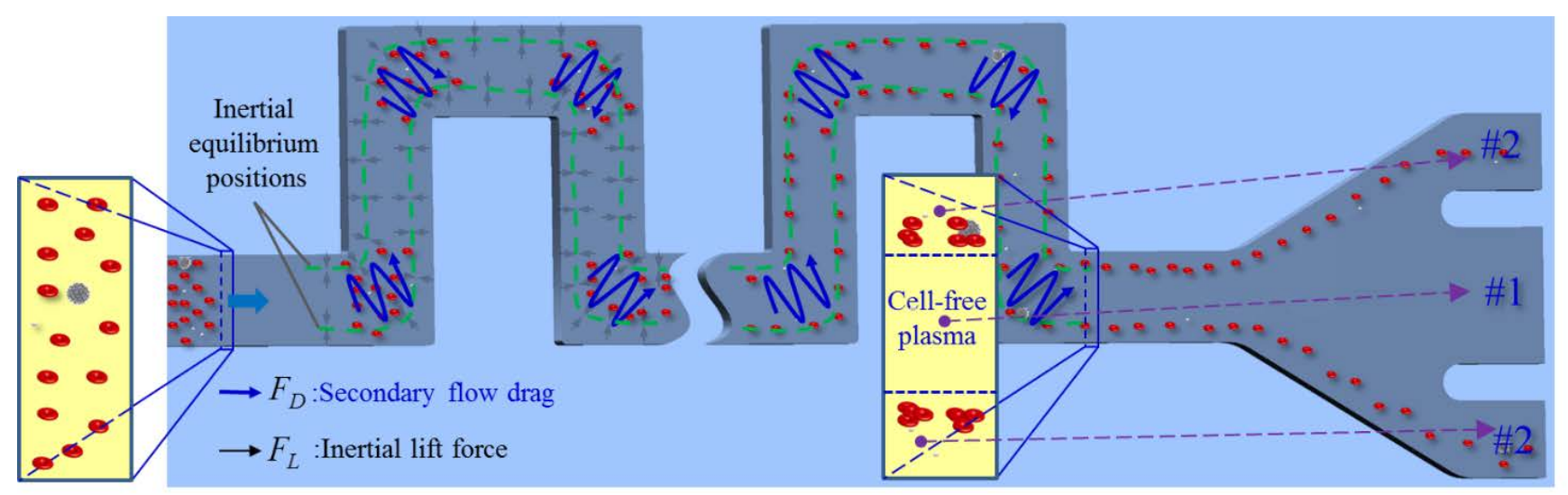

(a)

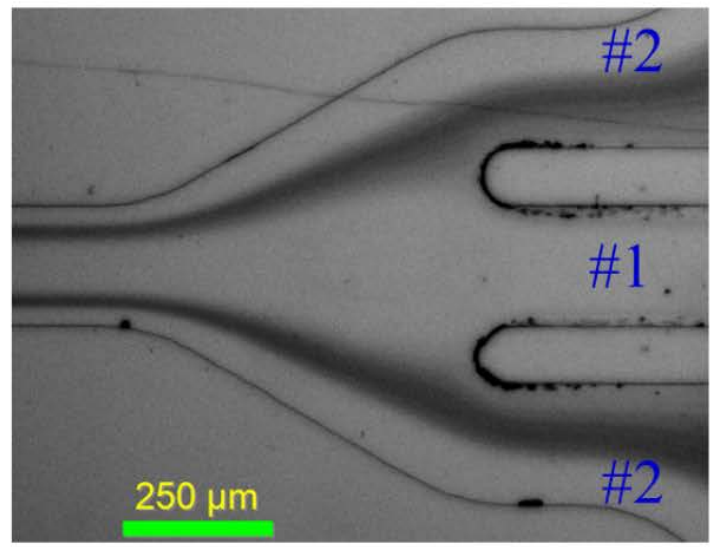

(b)

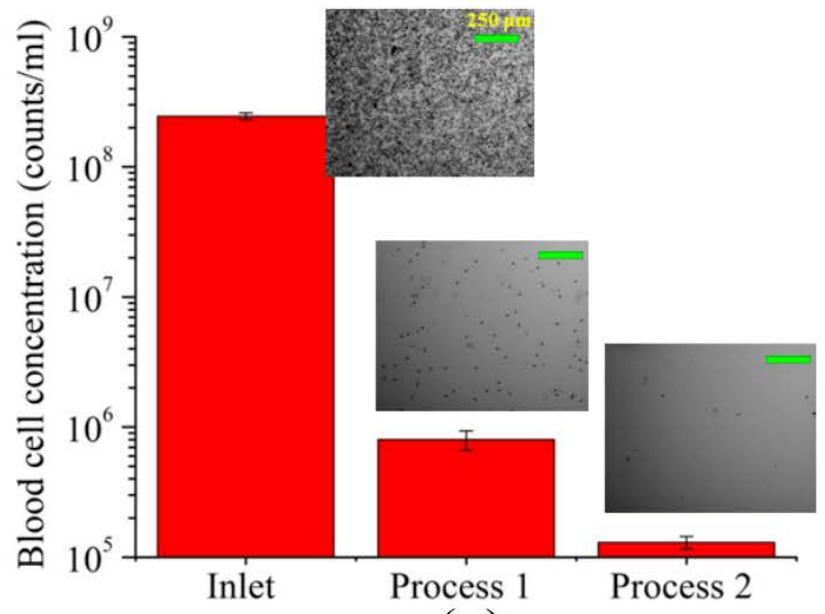

(c)

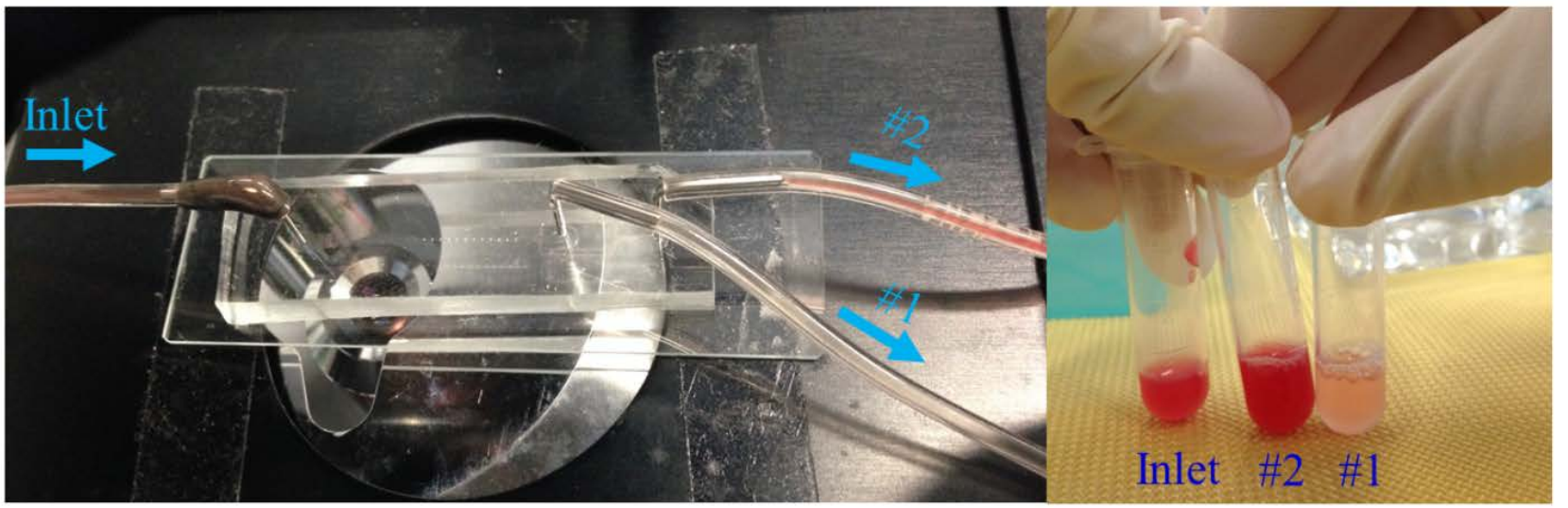

(d)

Fig. 5 (a) Schematic illustration of the extraction of plasma in the serpentine channel; (b) Bright field image of filtration of blood cells at the outlet; (c) Concentration of blood cells after each process, inserted with bright field images of blood sample before and after each filtration. In the second process, the input blood sample is blood plasma obtained from the first process. Error bars represent standard deviation of three measurements in 5 hemocytometer. (d) (Left) Working image of the microfluidic device, one can clearly observe that the tubes of outlet \#1 is clear, indicating barely red blood cells passing through, while tubes of inlet and outlet \#2 are in red colour, filled with massive red blood cells; (Right) Optical images of input blood sample and two collections from each outlets. 

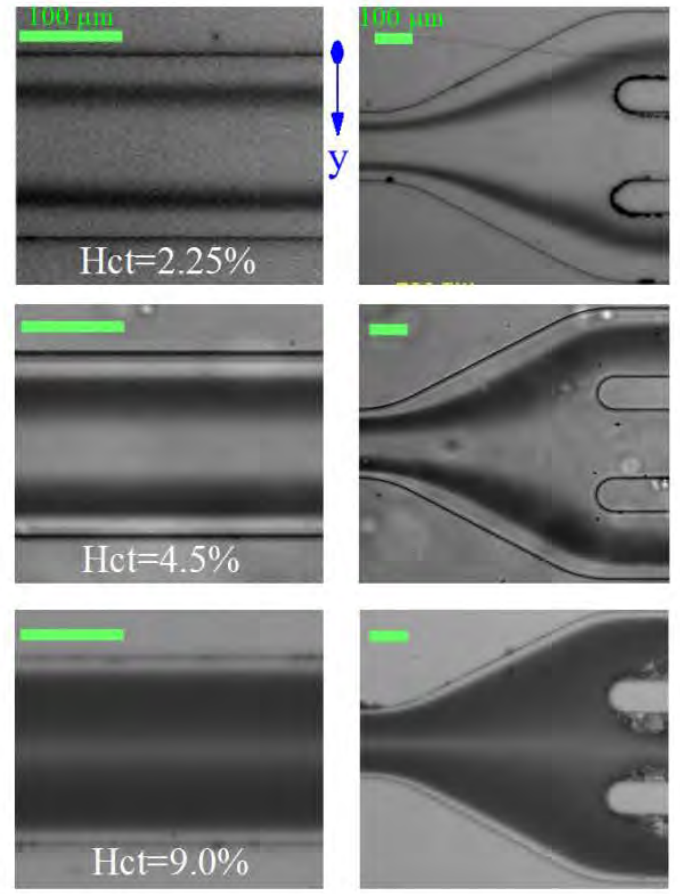

(a)

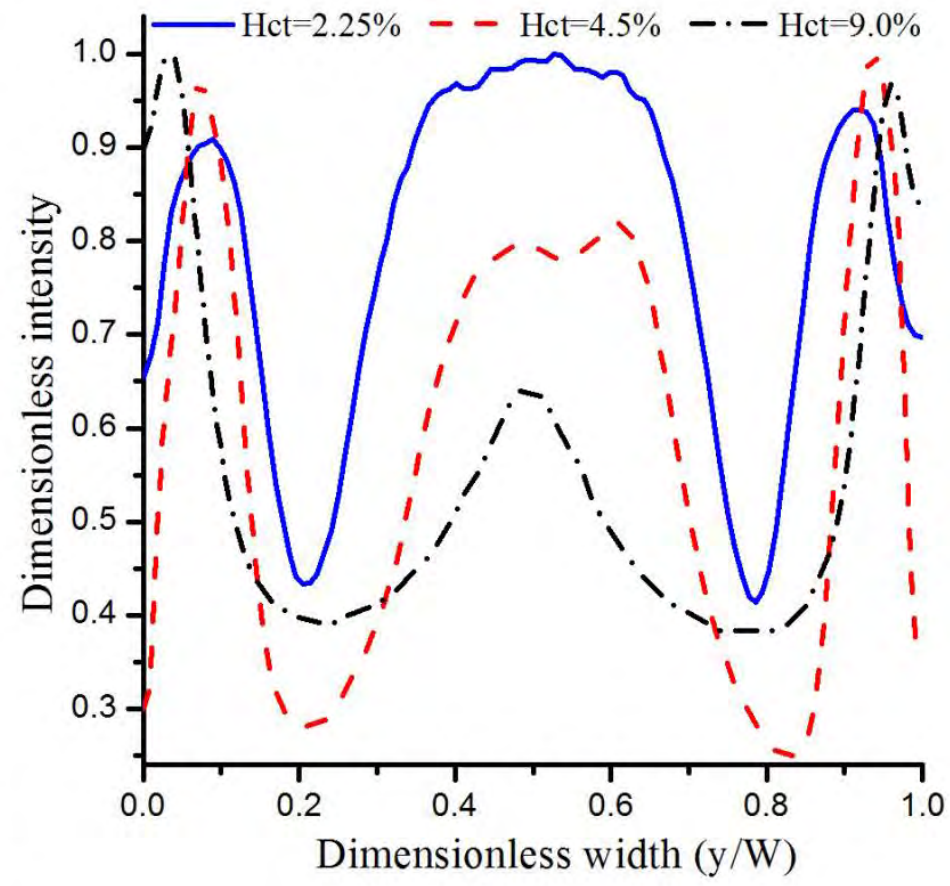

(b)

Fig. 6 Effects of blood haematocrit (Hct) on two sided inertial focusing. (a) The bright field images of blood cells focusing at the end of serpentine channel (left) and bifurcation outlet (right). (b) The bright field intensity profile at the end of serpentine channel along the channel width. It should be noted that in bright field images, the higher the intensity, the less cells occupy, allowing more illuminating light to be captured by camera. 


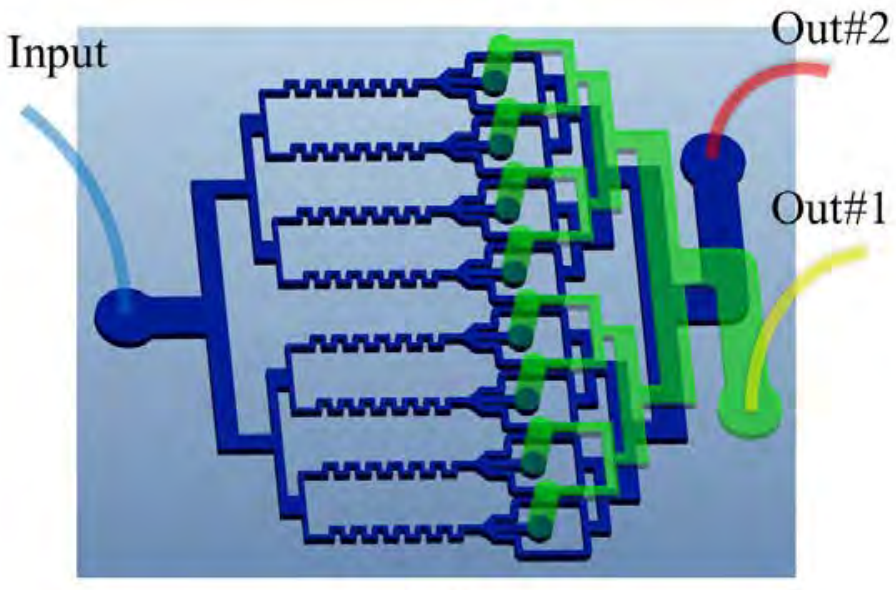

(a)

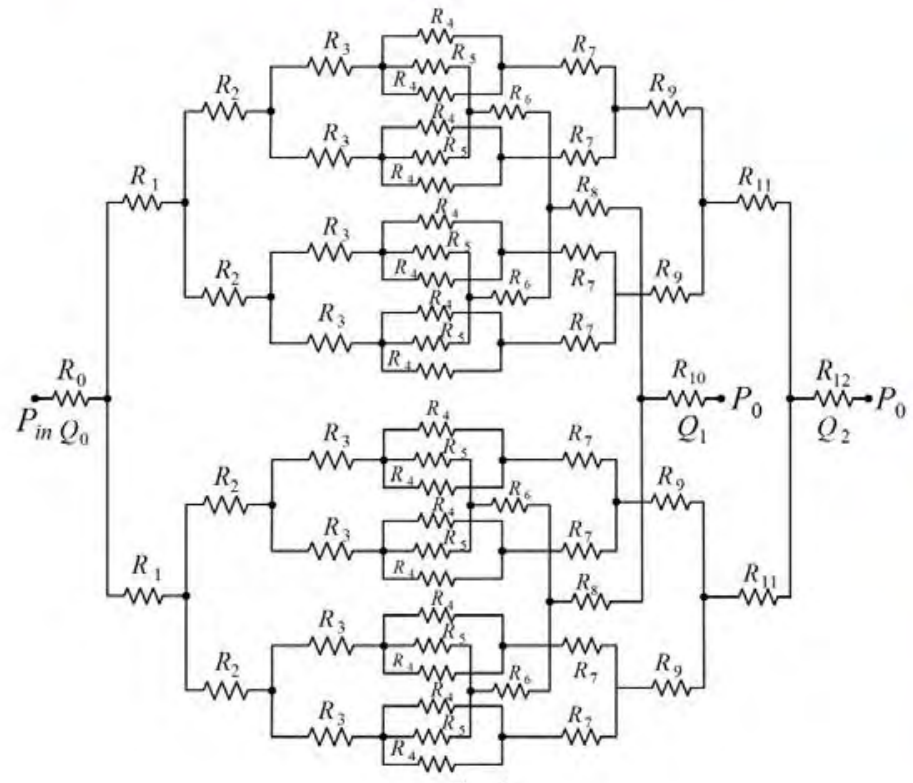

(c)

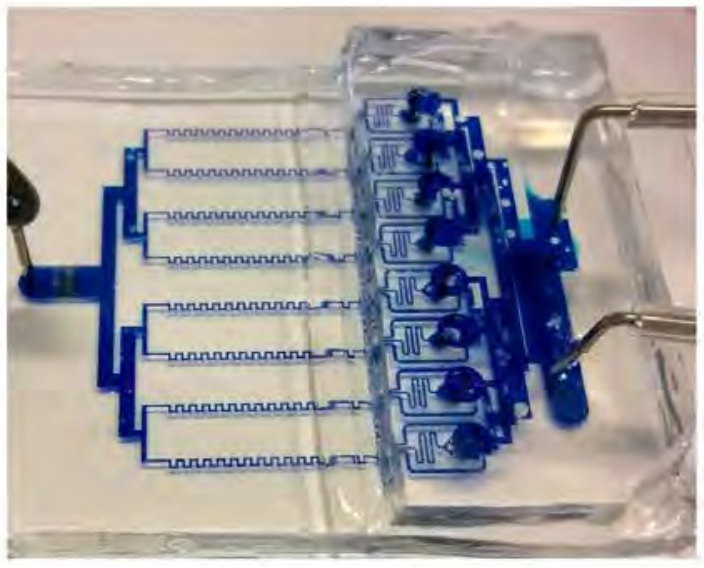

(b)

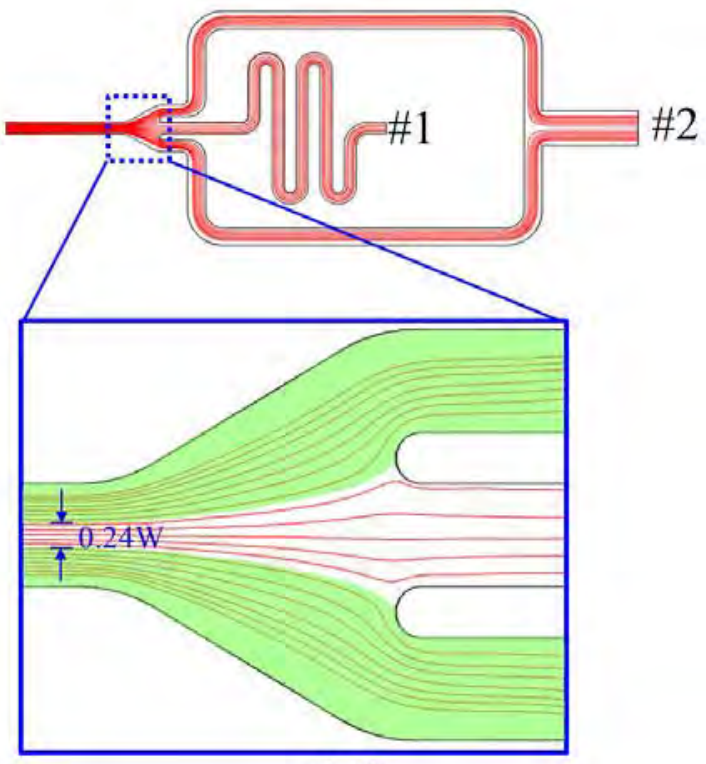

(d)

Fig. 7 (a) Schematic structure of the parallelized microfluidic device with eight serpentine channels; (b) The picture of fabricated parallelized microfluidic device. The blue food dye was injected into the device for better visualization of micro-channel structure; (c) Fluidic circuit of the parallelized microfluidic device; (d) Simulated flow field within one trifurcation outlet unit. 